\title{
Editorial
}

\section{Contribuições da Psicologia para a reflexão sobre o contemporâneo}

Estamos disponibilizando o número 39 do volume 18 da Paidéia: Cadernos de Psicologia e Educação, vinculada ao Programa de Pós-graduação em Psicologia da Faculdade de Filosofia, Ciências e Letras de Ribeirão Preto da Universidade de São Paulo - FFCLRP-USP. Com este fascículo damos prosseguimento à nossa missão de dar visibilidade para temas que preocupam a sociedade contemporânea e que, ao ingressarem no espaço cotidiano, afetam a vida das pessoas e convidam à reflexão sobre o tempo presente.

O fascículo é aberto com o trabalho Paidéia: Cadernos de Psicologia e Educação: Relatório de Gestão 2007, de Manoel Antônio dos Santos, Lucy Leal Melo-Silva e Eduardo Name Risk, que torna público e transparente o sistema de avaliação utilizado pela revista para a qualificação dos manuscritos. Além de reiterar os avanços alcançados, que permitiram consolidar uma trajetória de trabalho contínuo e consistente, o Relatório oferece elementos que permitem diagnosticar os aspectos que irão requerer maior atenção do Corpo Editorial no próximo período, com vistas ao aprimoramento do periódico.

Dos 13 artigos publicados neste número da Paidéia, 12 são de autores brasileiros e um, de autoria internacional. Os estudos, a despeito da diversidade de temas e dos contornos teórico-metodológicos que delineiam, organizam-se em torno de alguns eixos fundamentais, reforçando o compromisso de mantermos um olhar atento para questões candentes da agenda contemporânea.

A primeira vertente aborda a relação do homem com o ambiente, a partir de pesquisas enfeixadas em uma seção temática (Dossiê) e um estudo teórico sobre o impacto das catástrofes naturais. A segunda vertente abrange questões contemporâneas relativas à criança e ao jovem que transitam por diferentes cenários: escola, universidade e hospital, em suas múltiplas interações sociais. É abordada a questão da violência contra a criança, o preparo da crian- ça para cirurgia e o dilema do adolescente frente à escolha da atividade profissional. Também é focalizado o jovem portador de deficiência em seu processo de inserção social universitária, a construção das representações sociais da educação escolar, a orientação de pais de crianças com dificuldades de aprendizagem e as potencialidades de aprendizagem informal contidas nos videogames. A perspectiva dos educadores também é contemplada, em estudo que busca compreender como professores lidam com a deficiência e as demandas de inclusão. E no cenário da segregação social do sofrimento humano são investigadas práticas de letramento em um hospital psiquiátrico.

Seguem-se os artigos, divididos em seção especial, com três artigos, seção de pesquisas empíricas, com oito trabalhos, e a de pesquisa teórica, com dois artigos.

O conjunto de Pesquisas Empíricas que compõem este número da Paidéia é aberto com o Dossiê: Pessoa e Ambiente, as duas faces da mesma moeda. Em sua Apresentação, Isolda de Araújo Günther, da Universidade de Brasília, introduz os estudos que compõem essa seção temática.

No primeiro artigo, Psicologia Ambiental, Psicologia do Desenvolvimento e Educação Infantil: Integração possível?, Mara Campos-de-Carvalho e Tatiana Noronha de Souza, da Faculdade de Filosofia, Ciências e Letras de Ribeirão Preto da Universidade de São Paulo, focalizam a organização espacial em creches. $\mathrm{O}$ estudo aproxima linhas de pesquisa sobre arranjo espacial em salas de crianças, sobre uma escala norte-americana de avaliação de qualidade de ambientes infantis coletivos e sobre a análise de princípios de qualidade de creches em documentos nacionais e estrangeiros.

Em Reflexões sobre o comportamento infantil em um pátio escolar: $O$ que aprendemos observando as atividades das crianças, Odara de Sá Fernandes e Gleice Azambuja Elali, da Universidade Federal do Rio Grande do Norte, buscam compreen- 
der os diferentes tipos de relações infantis estabelecidas com o ambiente de um pátio escolar, bem como a interação entre crianças durante o recreio. Ao concluírem, as autoras apontam a necessidade de reflexão sobre o planejamento dos pátios escolares, de modo a maximizar a qualidade de vida das crianças.

Concluindo o dossiê, no artigo Ambiente de moradia e controle primário em idosos, de Hilma Tereza Tôrres Khoury, da Universidade Federal do Pará, e Isolda de Araújo Günther, da Universidade de Brasília, relata um estudo que investigou a relação entre ambiente de moradia e duas modalidades de controle percebido. Os resultados oferecem aportes relevantes para que se reflita sobre as necessidades de liberdade de ação e privacidade em idosos.

Em Abordagem bioecológica e narrativas orais: Um estudo com crianças vitimizadas, Heliana Castro Alves, da Universidade Federal do Triângulo Mineiro, e Maria Luisa Guillaumon Emmel, da Universidade Federal de São Carlos, propõem uma análise multifatorial do fenômeno da violência e de seu impacto no desenvolvimento emocional infantil. Crianças vítimas de violência doméstica e seus cuidadores foram investigados e os resultados sugeriram que narrativas orais podem servir como suporte sensível para despertar na criança conteúdos relacionados às vivências pessoais.

O caráter terapêutico da escrita: Práticas de letramento em um hospital psiquiátrico, da autoria de Leda Verdiani Tfouni, Anderson de Carvalho Pereira, Filomena Elaine de Paiva Assolini, Milena Sarti e Alessandra Adorni, da Faculdade de Filosofia, Ciências e Letras de Ribeirão Preto, da Universidade de São Paulo, apresenta um relato de pesquisa que investigou práticas de escrita em um trabalho de alfabetização realizado em um hospital psiquiátrico. Com base no referencial da Análise do Discurso, os autores postulam o caráter terapêutico da escrita face à situação de asilamento psiquiátrico.

O artigo Escala de Auto-eficácia para Atividades Ocupacionais: Construção e estudos exploratórios, de Maiana Farias Oliveira Nunes e Ana Paula Porto Noronha, da Universidade São Fran- cisco, apresenta resultados empíricos derivados da construção e validação de uma escala de avaliação da auto-eficácia para atividades ocupacionais e as fontes de auto-eficácia associadas (EAAOc). Essa escala é aplicada no contexto da Orientação Profissional. São apresentados os resultados relativos às propriedades psicométricas, que indicam a viabilidade do uso do instrumento no contexto brasileiro.

Na seqüência, com o artigo Preciso estudar para ser alguém: Memória e representações sociais da educação escolar, Luciene Alves Miguez Naiff, da Universidade Salgado de Oliveira, Celso Pereira de Sá, da Universidade do Estado do Rio de Janeiro, e Denis Giovanni Monteiro Naiff, da Universidade Federal Rural do Rio de Janeiro, abordam as teorias que tratam da memória social e das representações sociais. O estudo discute o papel da escola como agente de inclusão/exclusão nas memórias de vida de mães e filhas.

$\mathrm{O}$ artigo Inserção social universitária: Uma investigação com base no átomo social mínimo, de Juliana Cal Auad e Maria Inês Gandolfo Conceição, da Universidade de Brasília, propõe-se a mapear as redes sociais de alunos universitários com deficiência física, a partir de uma leitura psico-dramática, bem como identificar como o aluno avalia sua inserção a partir dos papéis desempenhados. Foi elaborado um instrumento, denominado de átomo mínimo, aplicado a estudantes universitários com deficiência física. Os resultados oferecem subsídios para o planejamento de políticas de inclusão universitária.

Seguindo na trilha da deficiência e contexto escolar, o artigo Qual é o lugar do aluno com deficiência? $O$ imaginário coletivo de professores sobre a inclusão escolar, de Camila Ferreira de Ávila, Miriam Tachibana e Tânia Maria José Aiello Vaisberg, da Pontifícia Universidade Católica de Campinas, investigou o imaginário coletivo de professores de ensino superior sobre inclusão escolar. Foram entrevistados 12 docentes dos cursos de Letras e de Pedagogia, utilizando-se do Procedimento DesenhosEstórias com Tema como recurso mediador-dialógico. Os resultados sugerem que, além de informações téc- 
nicas, o processo de inclusão escolar demanda um espaço de cuidado emocional aos professores.

No artigo Aprendizaje implícito en usuarios intensivos de videojuegos, de Lucio Rehbein Felmer, Paula Alonqueo Boudon e Michael Filsecker, da Universidad de La Frontera, Temuco, Chile, é focalizado o potencial de aprendizagem implícita dos videogames. Comparou-se o desempenho de jogadores intensivos, moderados e não-jogadores, em duas tarefas experimentais. Os resultados encontrados sugerem que os jogadores intensivos e moderados têm facilidades para captar regularidades implícitas na tarefa.

$\mathrm{O}$ artigo Programa de intervenção para pais de crianças com dificuldades de aprendizagem: Um estudo preliminar, de Andréia Bevilacqua Rolfsen e Cláudia Maria Simões Martinez, da Universidade Federal de São Carlos, descreve uma proposta de intervenção na modalidade de um programa psicopedagógico de orientação dirigido a pais e familiares responsáveis por crianças com dificuldades de aprendizagem. Os resultados evidenciaram que o Programa tem qualidades satisfatórias quanto à forma e conteúdo.

As Pesquisas Teóricas que compõem este número da Paidéia são introduzidas pelo artigo Preparação psicológica para a cirurgia em pediatria: Importância, técnicas e limitações, da autoria de Camilla Volpato Broering e Maria Aparecida Crepaldi, da Universidade Federal de Santa Catarina. Esse estudo apresenta uma revisão crítica da literatura sobre programas e técnicas de preparação psicológica para cirurgia em crianças. Também são focalizados os limites da pesquisa realizada nessa área.

$\mathrm{O}$ artigo Enfrentamento de desastres naturais: $O$ uso de um coping coletivo, de Fernanda Menna Barreto Krum e Denise Ruschel Bandeira, da Universidade Federal do Rio Grande do Sul, aborda o impacto sofrido pelos indivíduos e pela comunidade atingida por desastres naturais. As estratégias de coping mobilizadas para o ajustamento às condições adversas resultantes dos desastres naturais são investigadas a partir do modelo multi-axial de coping de Hobfoll, que introduz uma perspectiva social ao fenômeno, na medida em que vincula o indivíduo ao seu contexto de vida, o que permite postular um conceito de coping coletivo.

Esse número se encerra com a resenha Treinamento, desenvolvimento e educação: Tendências no estilo de gestão das organizações, elaborada por Thaís Zerbini, da Faculdade de Filosofia, Ciências e Letras de Ribeirão Preto da Universidade de São Paulo. A autora discute o livro publicado pela editora Artmed e organizado por Jairo Eduardo Borges-Andrade, Gardênia da Silva Abbad e Luciana Mourão, intitulado Treinamento, desenvolvimento e educação em organizações e trabalho: Fundamentos para a gestão de pessoas. A obra apresenta contribuições valiosas para a Psicologia Organizacional nesses tempos de reorganização das forças produtivas e de transição das relações de trabalho no contexto do capitalismo globalizado.

É inegável que, ao afinar a sintonia com temáticas de impacto, a Paidéia reforça seu compromisso com o acolhimento de linhas e perspectivas diversificadas, empenhando-se para se consolidar como um veículo de difusão e diálogo do conhecimento nas áreas da Psicologia e da Educação e em suas interfaces com áreas afins. Com esse espírito de abertura à diversidade, esperamos continuar contando com o apoio e reconhecimento de nossos pares da comunidade científica brasileira.

Lembramos que a revista está disponível na Scientific Eletronic Library Online (SciELO), na qual é denominada de Paidéia (Ribeirão Preto). Como é do conhecimento geral, a SciELO (www.scielo.br) é uma biblioteca eletrônica virtual que abrange uma coleção selecionada de periódicos científicos brasileiros. Essa facilidade de acesso ao conteúdo dos artigos permite que a revista cumpra o seu papel de periódico científico acessível a um maior número de leitores, incorporando ferramentas compatíveis com os recursos disponibilizados na era da informação.

Temos a certeza de que estamos entregando ao público uma amostra expressiva de estudos científicos qualificados. Os frutos que vêm sendo colhidos sem dúvida se devem ao entusiasmo que anima o corpo 
12

editorial e a equipe técnica. É preciso reiterar que a manutenção de um periódico da qualidade da Paidéia é uma empreitada coletiva. Para sustentar a vida de uma revista é preciso contar com essa disposição de revitalizar o legado e reinventar a tradição a cada nova etapa do percurso percorrido. 